by which man can live, finding life good, and proud in the faith that human and cosmic destiny entwine".

Such being Mr. Wellbye's philosophy, his ethic is realistic. Goodness is appropriate action-action naturally taken if the circumstances are envisaged as they actually are, and not simply as they appear to a vision limited and distorted by self-interest. If conduct is based on valuations or estimates of fact which are false, disaster inevitably follows, for successful action proceeds from a proper adjustment to reality. Thus desire has to be revised and corrected in the light of understanding, which is defined as "the ability to see through the meaningless world of appearance to the significant world as it is in relation to human activity". Thus Mr. Wellbye's scheme of things gives an absorbing purpose to human life and bases conduct upon an understanding of reality.

It will be seen that the view of humanity outlined in these pages is a favourable one, and this in spite of the strong temptation which present circumstances offer to take a contrary view. Unfortunately, much orthodox religious apologetic is now taking the pessimistic point of view, which is also the obvious one. Mr. Wellbye does not base his views on mere sentimentalism but on the anthropological researches which have exploded the popular myth that primitive man was a savage cave-dwelling individualist, but established him rather as a kindly co-operative creature, who had to be educated in cruelty by civilization. That our own civilization educates us in egoism can scarcely be denied. If institutions are the product of man, it is no less true that man is also the product of his institutions.

Mr. Wellbye, though one can sympathize with his motives, is possibly less than fair to the traditional religious point of view ; for example, we doubt if any instructed Christian would really hold "that what is good and what is wicked in human conduct rest finally on the arbitrary will of God". He would be much more likely to say with Mr. Wellbye himself that morality is behaving in accordance with the nature of things, about which there is certainly nothing arbitrary. Nor is it historically true that "the Christian Church has invented the category of sin". Sin is indeed a specifically religious and not merely a moral conception, but it is one which was widespread in the pre-Christian period, as the works of Prof. Angus, whom Mr. Wellbye names in his bibliography, show. The fact that the idea has been over-stressed does not divest it of truth. Mr. Wellbye emphasizes the importance of sensitiveness as a means of enriching personality, and the absence of all 'sense of sin' is a form of moral insensitiveness. It is not only physical ills, such as a toothache, that make a normal man feel uncomfortable. Mr. Wellbye also speaks of the capacity to absorb and use our experiences so that they change us; one of the positive achievements of the traditional religion has been that it has enabled people to convert adverse and disagreeable experiences into a means of enriching life and endowing it with new graces. There are those who, "going through the vale of misery use it as a well, and the pools are filled with water". Too many critics of the traditional religion have failed to recognize that it has satisfied a far larger variety of human needs than has any ad hoc system of ideas. Christianity is a pool where elephants may swim as well as lambs drink, and seems a different place to either. Perhaps Renan was not far wrong in saying that few people have the right to disbelieve in it.
The fact is that the constructive half of Mr. Wellbye's book is better than the critical half; and that is a good deal more than can usually be said of books of this character. His attempt to outline a new way of looking at things (which is perhaps not so new after all) is vigorous and stimulating.

J. C. HARDWICK.

\section{HIGHER ALGEBRA}

\section{The Tutorial Algebra}

By Dr. William Briggs and Prof. G. H. Bryan. Revised and rewritten by Dr. George Walker. Vol. 2: Advanced Course. Fifth edition, revised and rewritten. Pp. viii +599 . (London: University Tutorial Press, Ltd., 1942.) 12s. $6 d$.

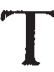
HE first volume of this standard work, published in 1940 in a revised and rewritten form, covered the algebra prescribed chiefly for the intermediate examinations of the University of London. The present book takes the work to a higher stage, and this additional volume was rendered necessary owing to the rapid expansion of the subject and, therefore, the need for the incorporation of a large quantity of new matter.

Volume 2 carries the course from infinite sequences and series to the theory of equations. The more advanced algebra required for London Intermediate Economics Examination and by students preparing for the several Higher School Certificate examinations is thus adequately provided in 542 well-filled pages of clearly written text. The binomial theorem, the exponential and logarithmic series, convergency, complex numbers, recurring series, summation, determinants, elimination and the theory of equations are all dealt with in a rigorous, comprehensive and skilful manner. The principles developed are excellently illustrated by aptly chosen examples, and the methods of solution are, in general, models of conciseness and elegance.

Indeed, in so many ways is the treatment so good that even more would seem to be desirable. This is particularly the case in the consideration of the biquadratic, although reference for more detailed discussion is given on p. 508. From a practical point of view, the quartic equation is becoming of increasing importance; yet rarely is a complete analysis of it to be found. It is therefore somewhat disappointing to find that no real development of the discriminant of the quartic, like the corresponding treatment of the cubic, is included in this valuable book. Incidentally, example (2) on p. 510 appears to require some clarification. Is the condition $a c-b^{2}>0$ sufficient to indicate the presence of at least two imaginary roots in a given biquadratic ? The equation, $x^{4}-4 x^{3}-35 x^{2}+122 x-168=0$, has two real roots, $-6,7$, and two imaginary roots, $\frac{1}{2}(3 \pm i \sqrt{ } 7)$; yet $a c-b^{2}$ is negative.

Only one other point need be mentioned : this concerns the determinantal equation on p. 511 which yields the reducing cubic in $\lambda \lambda^{\prime}$. As the text reads, the student is given no hint that this equation is the eliminant of the separate coeficients, $\lambda, \lambda^{\prime}, \mu, \mu^{\prime}$, after each of these has been expressed in terms of the unknown $\lambda \lambda^{\prime}$.

However, apart from these points and the few misprints noticeable, the revised edition of this work can be confidently recommended as a thoroughly good and sound course in modern algebra. F. G. W. Brown. 